Western University Scholarship@Western

1984

\title{
Contestable Markets Under Uncertainty
}

Elie Appelbaum

Chin Lim

Follow this and additional works at: https://ir.lib.uwo.ca/economicsresrpt

Part of the Economics Commons

Citation of this paper:

Appelbaum, Elie, Chin Lim. "Contestable Markets Under Uncertainty." Department of Economics Research Reports, 8421. London, ON: Department of Economics, University of Western Ontario (1984). 


\section{RESEARCH REPORT 8421 \\ CONTESTABLE MARKETS UNDER \\ UNCERTAINTY}

by
Elie Appelbaum and
Chin Lim

November, 1984

Elie Appe1baum
Department of Economics
York University
Downsview, Ontario, Canada

and
Department of Economics Library

DEC 61984

Universily of Western Oriario

Aclenovledgenents: We wish to thank John Chilton, Ignatious Horstmann, Peter Howitt and Glenn rlacDonald for helpful discussions. The research support for Chin Iin by the Social Sciences and Humanities Research Council of Canada is gratefully acknowledged. 


\section{INTRODUCTION}

In their recent work, Baumol, Panzar and Willig [1982] introduce and develop the theory of perfectly contestable markets, ${ }^{1}$ a theory which generalizes the standard theory of perfect competition. Their work provides a comprehensive analysis of the nature and structure of general production technologies (cost structure) and shows how these affect the structure of such contestable markets. Their work, thus, not only generalizes the competitive model providing an alternative and more general welfare standard, but also provides a framework which explains market structure endogenously.

The markets they analyse are contestable in the sense that access into the market is costless and, consequently, firms operate subject to "hit and run" entry. Given that in such an environment there are no "sunk" costs, there is clearly no scope for strategic behaviour involving various irreversible decisions ${ }^{2}$ (pre-commitments). Furthermore, since there is no uncertainty, so that all decisions are made with perfect information, there is also no role for information itself in determining production structures (techniques), and thus affecting market structure.

In this paper we present a model of a contestable market in which uncertainty and possible pre-commitments, in addition to cost conditions, play an important role. In fact, we show that cost conditions, uncertainty and pre-comnitments are inter-dependent; they are all affected and affect each other. Moreover, the fact that the market is contestable gives an additional and more important role to precomitments; they can be used not only to take advantage of more efficient production techniques, but also to affect the "degree of contestability" of the market.

The model we present evolves from the fast-growing literature on the theory of the firm under uncertainty. The initial developments in this literature (Sandmo [1971], Baron [1970], [1971], Leland [1972]) assumed that the firms ex ante decisions (pre-commitments, made before the resolution of uncertainty) are 
unalterable. Turnovsky [1973], however, appropriately fointed out that a more general formulation should allow the firm to modify its initial decisions, at additional costs, after it learns the true state of the world. (See also Hartman [1976], Epstein [1978].)

In our model, therefore, a firm (for example, an innovator) contemplating the introduction of a new product, can start making (decisions) commitments before market conditions are known, or can postpone such commitments and stay "flexible". In general, we show that there is a tradeoff between the informational advantage of later commitments and the production efficiency advantage of early commitments. There will, therefore, be some optimal "mix" of pre-commitments and consequent ex post adjustments. This, however, suggests that actual cost conditions will, at least, partially reflect the effects of uncertainty on the firm's behaviour; cost conditions will embody the firm's behaviour; cost conditions will embody the firm's reaction to uncertainty.

Contestability of the market will affect the firm in two interrelated ways. Its choice of precommitments will now be different since such precommitment can be used to change the "degree" of contestability.

The market we consider is assumed to be ex post perfect ly contestable. By this we mean that once the product has been introduced and the demand conditions become known, other firms may, if it is profitable to do so, freely enter the market and produce the same product, using the same ex post techniques and information as the incumbent. Thus, while the incumbent has the advantage of being able to make some decisions early (precommitments), the potential entrants have the advantage of being able to make their entry decision with more information (after uncertainty is resolved); they wili only enter if market conditions turn out to be "favourable", so that it is profitable to do so. 
We show that even when the market is not contestable (i.e. no potential entry) the incumbent will, in general, make some precommitment, taking advantage of a larger set of feasible activities available at earlier stages (possible advantages of early production). If the market is ex post contestable, so that anyone can enter if it is profitable to do so, the incumbent will change his precommitments and use them to affect the probability of actual entry. In particular, we show that the existence of potential entry will induce him to increase his precommitment, thus reducing the probability of entry. The probability of entry or the degree of contestability is therefore an endogenous variable determined by the optimal level of the incumbent's precommitment.

Secondly, if the stochastic demand is distributed as a general continuous density function, we show that then, although the optimal precommitment increases if the market is ex post contestable, it will not be optimal to increase it to such an extent that all entry is completely blocked. The equivalent to a "limit output" strategy ${ }^{3}$ will, therefore, not be optimal, a result that follows directily from the continuity of the density function which excludes the possibility of discontinuities and thus corner solutions. When uncertainty is characterized by discrete probability functions, we get a very rich set of possible outcomes which includes blockaded, partially, fully and unimpeded entry as special cases. 4

Finally, we show that the degree of market contestability or the probability of entry, will depend on ex ante and ex post cost conditions and the degree of uncertainty in the market. Specifically, we demonstrate that an increase in the efficiency of ex ante production or the increase in adjustment costs will make the market less contestable, whereas an increase in uncertainty will make it more contestable. Thus, for example, markets which are characterized by a great deal of uncertainty will be "more contestable" since the scope for using precommitments is reduced. 
II. MODEL WITHOUT POTENTIAL ENTRY

We first examine the case when there is no potential entry.

Consider a monopolist facing an increased demand function $p(q, \theta)$ where $q=\left(q_{1} \ldots q_{n}\right)$ is a vector of $n$ choice variables (say, output, level of advertising, quality, etc.) and $\theta$ is a random variable $\theta \in[\underline{\theta}, \bar{\theta}]$ with probability density function $\Phi(\theta)=\mathrm{d} \Phi(\theta)$. We assume that $\partial \mathrm{p} / \partial \theta>0$.

It is helpful to think of the problem as the one facing an innovator, contemplating the introduction of a new product. He can start the production of q (start making commitments) before demand conditions are known, or can wait until demand conditions are revealed. Clearly, the variables $q$, need not be entirely committed before $\theta$ is.revealed, nor do they have to remain completely uncommitted. In general the monopolist will make some commitments, $\mathrm{y} \geq 0$, ex ante and following the revelation of demand conditions (in the "next" period), he will adjust his pre-commitment by $z \geq 0$ ex post. Thus $q=y+z$ where we assume $y \geq 0, z \geq 0$ (i.e. pre-commitments are irreversable downwards.)

The optimal degree of pre-commitment will depend on the various parameters of the problem and in particular on the cost conditions underlying ex ante and ex post production and the distribution of the random variable $\theta$. It is clear however, that there is a trade-off between the informational advantages of latter commitments and the efficiency advantages of earlier pre-commitments which are due to the fact that the firm does not have to operate under a tighter time constraint. In other words, since ex post (last minute) production requires a speedier production process, we expect it to be less efficient, i.e., involve higher costs.

To demonstrate this let us consider the production technology of q. Let

$x_{i}(t)$ be a vector of inputs used in the production of $q_{i}$ at time $t$ and $q_{i}(\tau)$ the output of $q_{i}$ at time $\tau$. Let the technology of $q_{i}$ be given by the (Austrian) production possibilities $\operatorname{set}^{5} A_{i}:\left\{\left.x_{i}(t)\right|_{t=0} ^{T}, q_{i}(T)\right\} i=1 \ldots n$. 
In other words, an input (distribution) application of $\left.x_{i}(t)\right|_{t=0} ^{T}$ during periods $0 \ldots T$ will result, in an output of $q_{i}(T)$ after $T$ periods.

Suppose the firm wishes to have $q_{i}$ units of output $i$ and faces input prices $w_{i}(t)$. Its $i^{\text {th }}$ cost function is given by

$$
\min _{x_{i}(t), T}\left\{\sum_{t=0}^{T} w(t) x(t):\left\{\left.x_{i}(t)\right|_{t=0} ^{T}, q_{i}\right\} \varepsilon A_{i}\right\} \equiv c_{i}\left(q_{i}\right)
$$

where in (1), both the distribution of inputs over time, and the production period itself are chosen so as to minimize the costs of producing $q_{i}$.

Let us now assume that the firm faces a time constraint $T \leq T^{1}$. Its cost function will now be given by

$$
\min _{x_{i}(t), T}\left\{\sum_{t=0}^{T} w(t) x_{i}(t):\left\{\left.x_{i}(t)\right|_{t=0} ^{T}, q_{i}\right\} \varepsilon A_{i}, T \leq T^{1}\right\} \equiv c_{i}^{1}\left(q_{i}\right)
$$

and clearly we must have

$$
c_{i}\left(q_{i}\right) \leq c_{i}^{1}\left(q_{i}\right)
$$

Ex post production, by definition, faces a tighter time constraint. Thus although it is informationally superior it is also technically inferior compared to early precommitments. The optimal mix of $y$ and $z$ will clearly balance out those two effects.

In order to focus on the choice of degree of commitment rather than the tradeoffs among the instruments $q$, we will focus on the case where $q$ is a scalar. The choice variable is, thus, thought of as the output level. The analysis can be extended, however, to a multi-dimensional case without affecting the spirit of the results. In addition, and for similar reasons, we also choose to work with the simplest possible cost function in order to bring out in the clearest manner the informational and technical tradeoff. 
We write the cost function as

$$
c=c_{y} y+c_{z} z \text { with } c_{z}>c_{y} \text {. }
$$

The difference $\left(c_{z}-c_{y}\right)>0$ reflects the higher costs that the monopolist must incur if he were to, ex post, produce over and above his ex ante production level y."

We should note that specifying cost conditions as in (4) not only simplifies the analysis, but it also enables us to concentrate on the effects of uncertainty on production choices (and actual cost structures) rather than the nature of the cost structure itself. In other words, alting taking a general cost structure will enable us to say something about how various cost structures affect market outcomes, this is not the purpose of this paper. Our interest here is to focus on the effects of uncertainty on the choice of ex ante and ex post production and hence the choice of the cost structure itself. Thus, in simplifying the cost structures as in (4), we are letting the firm have a choice among the different simplified structures.

Assuming the monopolist to be risk-neutral, his choice of $y$ and $z$ are such that his expected profit is maximized:

$$
\operatorname{Max}_{y \geq 0} E\left[\operatorname{Max}_{z \geq 0} R(y+z, \theta)-c_{y} y-c_{z} z\right]
$$

where $E$ is an expectations operator and $R(y+z, \theta) \equiv p(y+z, \theta)(y+z)$ is the revenue function which is assumed to be strictly concave in $(y+z)$. The above problem can be split into two stages. First, given any level y, optimal z solves the problem

$$
\operatorname{Max}_{z \geq 0} R(y+z, \theta)-c_{y} \dot{y}-c_{z} z \equiv \pi^{0}(y, \theta)
$$

and optimal y then solves the problem

$$
\operatorname{Max}_{y \geq 0} E\left[\pi^{\circ}(y, \theta)\right]
$$

The solutions to (6) and (7) will now be described. 
Ex post Production Adjustment

Define $R_{y}(y, \theta) \equiv \partial R(y, \theta) / \partial y$ as the marginal revenue function (and assume that $\left.\partial R_{y}(y, \theta) / \partial \theta>0\right)$. Let $y^{\circ}(\theta)$ be such that

$R_{y}\left(y^{0}(\theta), \theta\right)=c_{z}$.

The level $\mathrm{y}^{\circ}(\theta)$, at which the marginal revenue intersects the ex post marginal $\operatorname{cost} c_{2}$ as in (8), is assumed to be positive for all $\theta$ (see Figure 1). Hence $0<\mathrm{y}^{0}(\underline{\theta})<\mathrm{y}^{0}(\bar{\theta})$.

Further, let $\theta^{\circ}(y)$ be the value of $\theta$ that (for a given $y$ ) solves $R_{y}\left(y, \theta^{\circ}(y)\right)=c_{z}$. Thus, given any precommitted level of $y$, the optimal solution of $z$ (to problem

(6)) is :

$z= \begin{cases}y^{o}(\theta)-y \geq 0 & \text { if } \theta \geq \theta^{\circ}(y) \\ 0 & \text { if } \theta \leq \theta^{\circ}(y)\end{cases}$

Optimal Ex ante Production Without Potential Entry

Substituting the above solution for $z$ in (5) and then taking expectations with respect to $\theta$, the expected total profit becomes

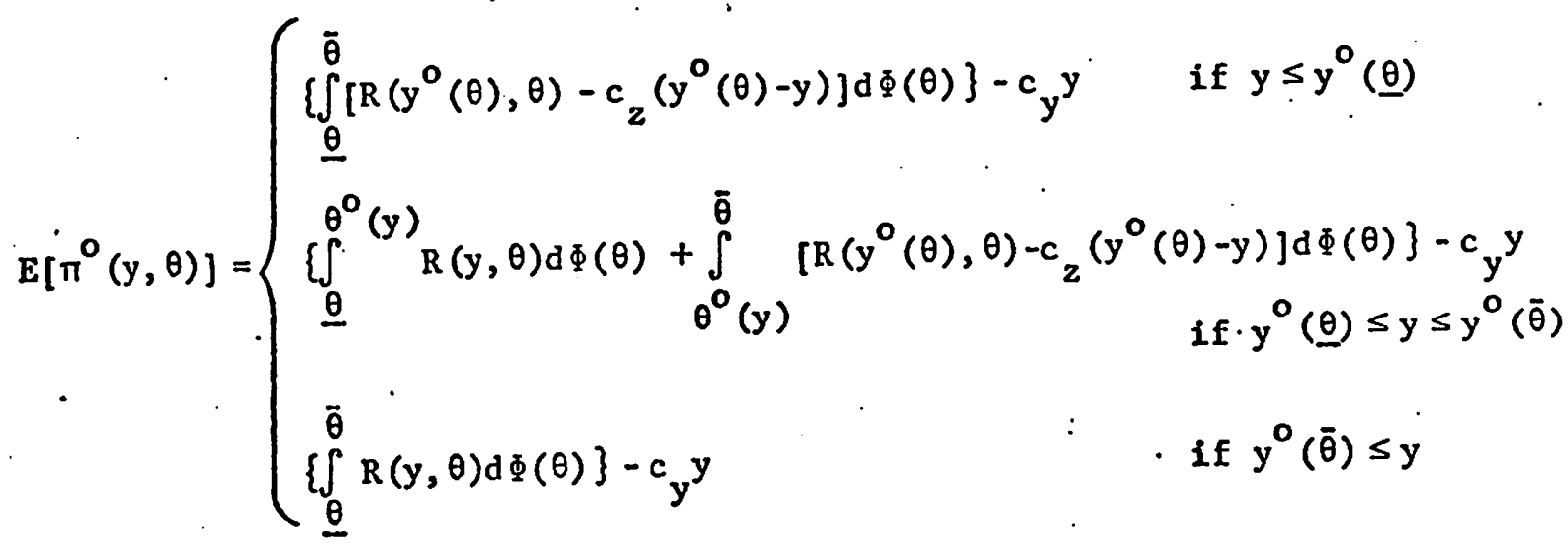

where $\theta^{\circ}(y)$ is defined above and thus satisfies $y^{\circ}\left(\theta^{\circ}(y)\right)=y$. 
Maximizing (10) with respect to y yields the necessary and sufficient ${ }^{6}$ condition:

$$
0=E\left[\mathbb{R}^{0}\right]-c_{y} \equiv \begin{cases}\left\{c_{z}\right\}-c_{y} & \text { if } y \leq y^{0}(\underline{\theta}) \\ \left\{\int_{\theta}^{\theta^{0}(y)} R_{y}(y, \theta) d \Phi(\theta)+\left(1-\Phi\left(\theta^{0}(y)\right)\right) c_{z}\right\}-c_{y} & \text { if } y^{0}(\underline{\theta}) \leq y \leq y^{0}(\bar{\theta}) \\ \left\{\int_{\theta}^{\theta} R_{y}(y, \theta) d \Phi(\theta)\right\}-c_{y} & \text { if } y^{0}(\bar{\theta}) \leq y\end{cases}
$$

This simply states that optimal y must equate the effective expected marginal revenue $E\left[\mathbb{R}^{0}\right]$ (the bracketed $\{$.$\} terms in r.h.s. of (11)$ ) with the marginal cost $c_{y}$.

In Figure 1 (where in $1(9)$ we have used a linear model for the sake of exposition), the $E\left[\mathbb{R}^{\circ}\right]$ schedule is shown to consist of a continuous and smooth curve given by $c_{2} K^{\circ} \overline{\mathrm{K}}^{\circ} \mathrm{M}$.

In the region $y \leq y^{\circ}(\underline{\theta})$, the optimal ex post production adjustment. (from (9)) is $z=y^{0}(\theta)-y \geq 0$ for all $\theta$. Thus the total output $(y+z)=y^{0}(\theta)$ is independent of $\mathrm{y}$. This implies that a unit increase in $\mathrm{y}$ is always accompanied by a corresponding unit reduction in $z$ with the consequence that it induces a benefit (due to cost-saving) of $c_{z}$ for all $\theta$. This explains the effective expected marginal revenue of $y$ production being $E\left[M^{\circ}\right]=c_{z}$ (the bracketed $\{$.$\} term in the first$ line of (11) or the line segment $c_{2} \mathrm{~K}^{0}$ in Figure $\left.1(\mathrm{~b})\right)$.

In the region $\mathrm{y}^{\circ}(\underline{\theta}) \leq \mathrm{y} \leq \mathrm{y}^{\circ}(\bar{\theta})$, let $\Theta \equiv[\underline{\theta}, \bar{\theta}]$ be partitioned into $\Theta^{\ell} \varepsilon\left[\underline{\theta}, \theta^{\circ}(\mathrm{y})\right]$ and $\Theta^{h} \varepsilon\left[\theta^{o}(y), \vec{\theta}\right]$ where $\theta^{o}(y)$ is defined by $y^{o}\left(\theta^{\circ}(y)\right)=y$. Then from (9), ex post production adjustment for $\theta \varepsilon \Theta^{l}$ is $z=0$ whereas for $\theta \varepsilon \Theta^{h}, z=y^{0}(\theta)-y \geq 0$. Thus, for those low states in $\Theta^{\ell}$, total output $(y+z)=y$ and for high states in $\Theta^{h}$, total output $(y+z)=y^{\circ}(\theta)$ is independent of $y$. Hence a unit increase in $y$ induces a benefit of $\mathrm{R}_{\mathrm{y}}(\mathrm{y}, \theta)$ for $\theta \varepsilon \Theta^{\ell}$ whereas it yields a benefit of $c_{z}$ (from cost-saving) for $\theta \in \mathbb{\Delta}^{\mathrm{h}}$. Consequent1y, within this range, the effective expected marginal revenue of $y$ production is $E\left[\mathbb{M}^{\circ}\right]=\int_{\theta}^{\theta^{\circ}(y)} R_{y}(y, \theta) d P(\theta)+\left(1-\Phi\left(\theta^{\circ}(y)\right)\right) c_{z}$ 
(the bracketed $\{$.$\} term in ine 2$ of (11) or the $\underline{k}^{0} \bar{k}^{0}$ curve ${ }^{7}$ in Figure $1(b)$ ). Finally, for $y$ in the region $y \geq y^{\circ}(\bar{\theta})$, ex post production adjustment (from (9)) is $z=0$ for all $\theta$. Hence total output $(y+z)=y$ for all $\bar{\theta}_{\bar{\theta}}$ so that the effective expected marginal revenue of $y$ is simply $E\left[M R^{\circ}\right]=\int_{\theta} R_{y}(y, \theta) d \Phi(\theta)$ (the bracketed $\{$.$\} term in line 3$ of (11) or the segment ${ }^{8} \bar{K}^{\circ} \frac{\theta}{M}$ in Figure $1(b)$ ).

It is important to note that the area under the $E\left[\mathbb{R}^{0}\right]$ schedule in Figure 1(b) does not fully capture the expected total revenue. The latter, as can be seen in the bracketed \{\} terms in (10), contains components which are independent of $\mathrm{y}$; these are precisely the appropriate 'constants of integration' which are not captured if one were to simply use the area under the $E\left[\mathrm{MR}^{\circ}\right]$ schedule in Figure $L(b)$ to describe the expected total revenue.

The properties of the optimal solution for $y$ and hence $z$ can now be easily inferred from (11) or Figure $1(\mathrm{~b})$. First, since the marginal adjustment costs $\left(c_{z}-c_{y}\right)>0$, the first line of equation (11) can never hold so that if $y^{*}$ is the optimum satisfying $(1 i)$, it is restricted to the range $y^{*}>y^{0}(\underline{\theta})$. The optimal ex post production adjustment (after defining $\theta^{0}\left(y^{*}\right)$ by $y^{*}=y^{0}\left(\theta^{0}\left(y^{*}\right)\right)$ ) is given by (9) which implies $z=0$ for $\theta \leq \theta^{\circ}\left(y^{*}\right)$ and $z>0$ for $\theta>\theta^{\circ}\left(y^{*}\right)$. In other words, optimal $y^{*}$ will always be large enough such that ex post adjustment will never occur in the poorer states $\left(\theta \leq \theta\left(y^{*}\right)\right)$ and, if it ever occurs, will only do so in the better states $\left(\theta>\theta^{\circ}\left(y^{*}\right)\right)$. Thus given the distribution of $\theta$, we can actually calculate the probability distribution of $z$.

Second, if the marginal adjustment costs $\left(c_{z}-c_{y}\right)>0$ is small such as when $c_{y}\left(e . g ., c_{y}^{a}\right)$ lies between $\underline{K}^{0}$ and $\bar{K}^{0}$ in Figure $L(b)$, the $y_{a}^{*}$ lies in the region $y^{0}(\underline{\theta})<y_{a}^{*}<y^{0}(\bar{\theta})$ with the result that ex post production adjustment will occur but only in the better states $\left(\theta>\theta^{\circ}\left(y_{a}^{*}\right)\right)$.

Finally, if $\left(c_{z}-c_{y}\right)>0$ is large such as when $c_{y}\left(e . g ., c_{y}^{b}\right)$ lies below $\overline{\mathrm{K}}^{\mathrm{o}}$ in Figure $1(\mathrm{~b})$, then optimal $\mathrm{y}_{\mathrm{b}}^{*}>\mathrm{y}^{\circ}(\bar{\theta})$ implying (from (9) that ex post adjustment $z=0$ for all $\theta$. Here the firm takes advantage of the low cost 


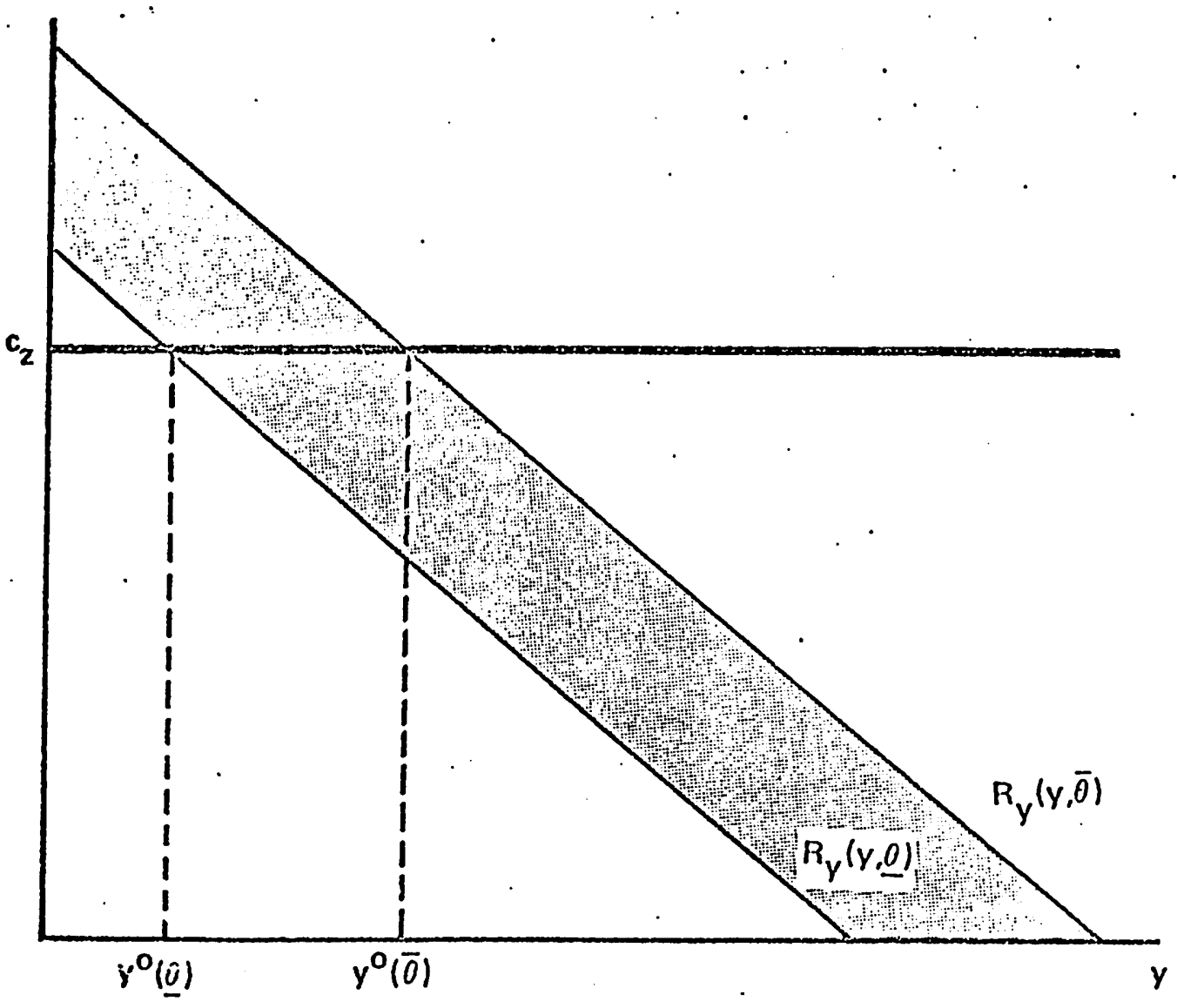

Figure $1(a)$

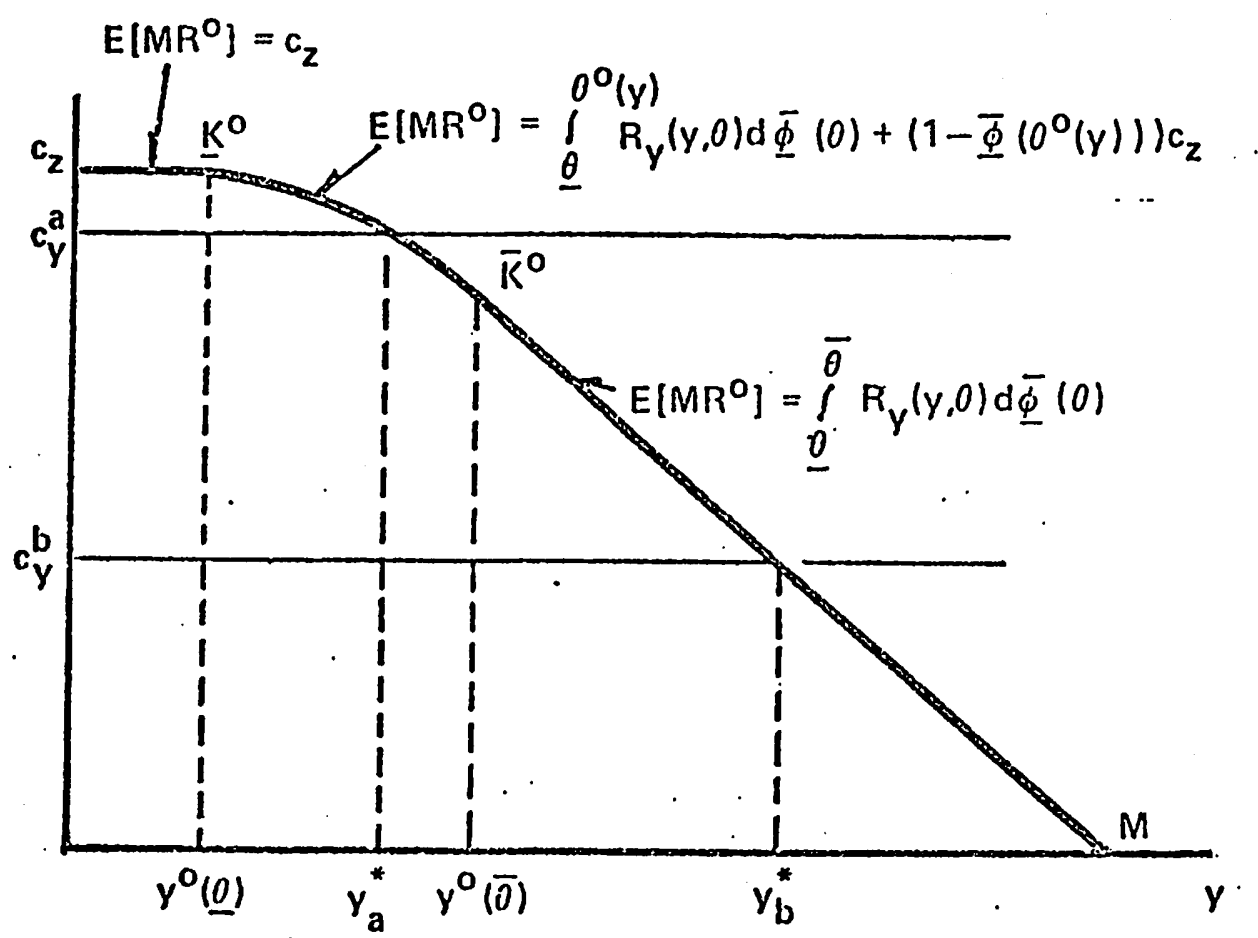

Figure $1(b)$ 
of ex ante production to produce a high level of $y$ and, because of the large ex post adjustment costs $\left(c_{z}-c_{y}\right)$, refrains from any ex post production adjustment.

Before we conclude this section let us consider the effects of. changes in the various parameters on the level of pre-commitment. First, from (11) or from Figure $1(b)$ it is obvious that $\partial y * / \partial c_{y}<0$. An increase in $c_{y}$ reduces the technical advantage of early production and will thus reduce the level of pre-commitment. Furthermore, as $c_{y}$ increases, the probability of an ex post adjustment increases $\left(\mathrm{d} P\left[\theta>\theta^{\circ}\left(\mathrm{y}^{*}\right)\right] / \mathrm{dC} \mathrm{y} \geq 0\right)$ and also the expected value of the adjustment increases $\left(\mathrm{dE}\left(\mathrm{z}^{*}\right) / \mathrm{dC} \mathrm{y} \geq 0\right)$.

Second, let the cost of ex post production increase by $\Delta C_{z}=C_{z}^{1}-C_{z}$. Then from (11) we get

$$
\begin{aligned}
\Delta E\left(\mathbb{R}^{0}\right) & =\int_{\theta^{o}\left(y, c_{z}\right)}^{\theta}\left(y, c_{z}^{1}\right) \\
& \geq \Delta c_{z}\left\{1-\Phi\left[\theta^{\circ}\left(y, c_{z}^{1}\right)\right]\right\} \geq 0 \text { al1 y }
\end{aligned}
$$

where $\theta^{\circ}\left(y, c_{z}^{1}\right)$ and $\theta^{o}\left(y, c_{z}\right)$ are the states of the world that will equate $R_{y}(y, \theta)$ with ex post marginal costs when the values of marginal costs are $c_{z}$ and $c_{z}$ respectively and the first inequality holds since for the range $\theta^{0}\left(y, c_{z}\right) \leq \theta \leq \theta_{0}\left(y, c_{z}^{1}\right)$, $\mathrm{R}_{\mathrm{y}}(\mathrm{y}, \theta) \geq c_{\mathrm{z}}$ for all $\mathrm{y}$. Thus, an increase in ex post costs will shift the expected marginal revenue curve (of $y$ ) up and will tend to increase the level of precommitment; that is, $\partial y * / \partial c_{z} \geq 0$. This is intuitively sensible; the increase in $c_{z}$ increases the relative efficiency of ex ante production so the firm is willing to take a greater "risk (by increasing $y$ ) and trade away more flexibility (informational advantage) for production efficiency. Furthermore, since the level of precomitment increases with $c_{z}$, it also follows that the probability of an ex post adjustment decreases, and the expected 
value of the adjustment decreases; i.e. $\mathrm{dE}\left(\mathrm{z}^{*}\right) / \mathrm{dc} \mathrm{z}_{\mathrm{z}} \leq 0$.

Finally, let us examine the effects of an increase in uncertainty. To be able to determine the effects of an increase in uncertainty on ex ante production, we usually need information about the shape of the revenue function and /or the distribution of $\theta$. If we are willing to assume "risk aversion" in $\theta$, in the sense that $R_{y}(y, \theta)$ is concave in $\theta$ (and not because firms have utility functions which are strictly concave in profit income), it follows, using the result of Rothschild and Stiglitz [1970], that an increase in uncertainty (mean preserving) will decrease the effective expected marginal revenue of $y, E\left[\mathbb{R}^{\circ}\right]$, and will thus reduce the level of precommitment. So, for example, if $\gamma$ is a parameterization of the density function, $\phi(\theta, \gamma)$, such that $\partial \phi(\theta, \gamma) / \partial \gamma$ is an (mean preserving) increase in spread, then $d E\left[M R^{0}\right] / d \gamma \leq 0$. Thus, concavity of $R_{y}(y, \theta)$ in $\theta$ implies that an increase in uncertainty will. reduce $y^{*}$. Again, this is what intuition would suggest; greater uncertainty $\mathrm{cn}$ one hand increases the effective cost of precommitments while, on the other hand, it increases the benefit of flexibility of later commitments. Hence, the firm will prefer a more flexible (less committed) position.

To see this, let $f(\theta)$ and $g(\theta)$ be two density functions and the corresponding expected marginal revenues $E_{f}\left[\mathbb{R}^{\circ}\right]$ and $E_{g}\left[M R^{\circ}\right]$. Then

$$
\begin{gathered}
E_{f}\left[M^{\circ}\right]-E_{g}\left[M^{\circ}\right]=E_{f}\left[R_{y}(y, \theta)\right]-E_{g}\left[R_{y}(y ; \theta) / \theta \leq \theta^{\circ}(y)\right] \\
+C_{z}\left\{G\left[\theta^{\circ}(y)\right]-F\left[\theta^{\circ}(y)\right]\right\} \quad \text { for ail } y .
\end{gathered}
$$

where $G$ and $F$ are cumulative probability functions. Integrating the right-hand side of (13) by parts yields

$$
E_{f}\left(M^{0}\right)-E_{g}\left(\mathbb{R}^{0}\right)=\int_{\theta}^{\theta}\left[\partial R_{y}(y, \theta) / \partial \theta\right][G(\theta)-F(\theta)] d \theta \text { for all } y \cdot
$$


Since $\partial \mathbb{R}_{y}(y, \theta) / \partial \theta>0$ by assumption, we get that $E_{f}\left(\mathbb{R}^{0}\right)-E_{g}\left(\mathbb{R}^{0}\right) \geq 0$ if $G(\theta) \geq F(\theta)$ all $\theta \leq \theta^{\circ}(y)$, which is precisely the condition that the distribution $f$ will exhibit first-order stochastic dominance over $g$ in the range $\theta \leq \theta^{\circ}(y) .^{9}$ Thus an increase in uncertainty according to first-order stochastic dominance will shift down the $E\left[M R^{\circ}\right.$ schedule and hence the optimal level of precommitment $y *$. If, in addition, we are willing to assume "risk aversion" in $\theta$ (i.e. $R_{y}(y, \theta)$ is concave) then by further integrating (14) by parts, it is easily verified that $E_{f}\left(M^{0}\right) \geq E_{g}\left(M^{0}\right)$ if $f$ exhibits second-order stochastic dominance, $i . e .$, if $g$ is a mean preserving spread of $f$. In this case, again, an increase in uncertainty will shift the $E\left[\mathbb{R}^{\circ}\right]$ curve down and will, therefore reduce $y^{*}$. And as a result, the probability of ex post production and its expected value will increase. Thus, an environment which is characterized by a greater degree of uncertainty will reduce the firm's willingness to make early commitments. 


\section{EX POST CONTESTABLE MARKET}

We now introduce into our model the existence of potential entry and analyse the effects of such potential entry on the behaviour of the monopolist. We consider a market which is ex post contestable, that is, once the product is introduced and demand conditions become known, other firms may enter the industry if it is profitable to do so. At this juncture, recall (from section II) that it is the tighter time constraint that yields the cost differences between the ex ante and ex post technologies. Hence the model described here pertains to a product whose market lasts only a finite period. In such a market, the incumbent obviously has the advantage of being able to produce (early) according to the ex ante technology. Potential entrants, on the other hand, have the advantage of being able to make entry decisions after uncertainty is resolved. Ex post, both incumbent and entrants face the same technology $\left(c_{z}\right)$ and information 10 $(\theta)$. The market is, therefore, perfectly contestable ex post, in the sense that there are no barriers to (ex.post) entry and the ex post solution is a zero-profit equilibrium.

Being able to make the first move the incumbent will take potential entry into account in his choice of the ex ante output. In particular, since the probability of entry depends on the pre-commitment, he will take this dependence into account and, in fact, will choose optimally the probability of entry he wishes to entertain. To what extent his strategy will deter entry remains to be seen. It is, however, clear that reducing the probability of entry has a "price", namely, the greater risk involved in greater pre-commitments. We should thus, in general, expect that some positive probability of entry may be optimal.

Ex Post Equilibrium

We begin the analysis by first considering the nature of the ex post entry equilibrium. Given any level of the incumbent's ex ante production $y$, ex post 
entry will occur as long at the ex post demand price $p(y, \theta)>c_{z}$ (the marginal cost of entrants); and entry will proceed until the total ex post output ${ }^{11} z>0$ obtains only zero profit: $p(y+z, \theta)=c_{z}$. Conversely if the incumbent's $y$ is such that $p(y, \theta) \leq c_{z}$, ex post entry will not occur $(z=0)$ since doing so would yield negative profit. Hence, the ex post equilibrium requires all ex post production to yield non-positive profit:

$$
p(y+z, \theta) \leq c_{z}
$$

To formally characterize the ex post equilibrium level of production $z$, let $y^{n}(\theta)$ be defined by

$$
p\left(y^{n}(\theta), \theta\right)=c_{z}
$$

If $y \leq y^{n}(\theta)$, then from (16) we have $p(y, \theta) \geq c_{z}$ implying that for ex post equilibrium, $p(y+z, \theta)=c_{z}$, to be re-established, it is necessary that $z=y^{n}(\theta)-y \geq 0$. If, conversely, $y \geq y^{n}(\theta)$, then from (16) we have $p(y, \theta) \leq c_{z}$ implying that equilibrium condition (15) can only be satisfied for $z=0$. Defining $\theta^{n}(y)$ as the value of $\theta$ that solves $\dot{p}(y, \theta)=c_{z}$ (i.e. $y^{n}\left(\theta^{n}(y)\right)=y$ ) we then have

$$
z=\left\{\begin{array}{cc}
y^{n}(\theta)-y \geq 0 \text { if } \theta \geq \theta^{n}(y) \\
0 & \text { if } \theta \leq \theta^{n}(y)
\end{array}\right.
$$

Notice that the ex post equilibrium solution for $z$ in (17) differs from the optimal solution for $z$ in (9) where there is no potential entry. The reason is that $y^{n}(\theta)>y^{0}(\theta)$, since $R_{y}(y, \theta)<p(y, \theta)$ for all $y$. and $\theta$. This is easily seen in Figure 2(a).

\section{Optimal Ex ante Production Given An Ex post Contestable Market}

Faced with the stochastic entry constraint given by (17), the incumbent, in his choice of ex ante production $y$, does not take the primitive demand price distribtuion $p(y, \theta)$ as the relevant environmental data. Instead, what is of relevance to him is the entry-constrained demand price distribution given by 


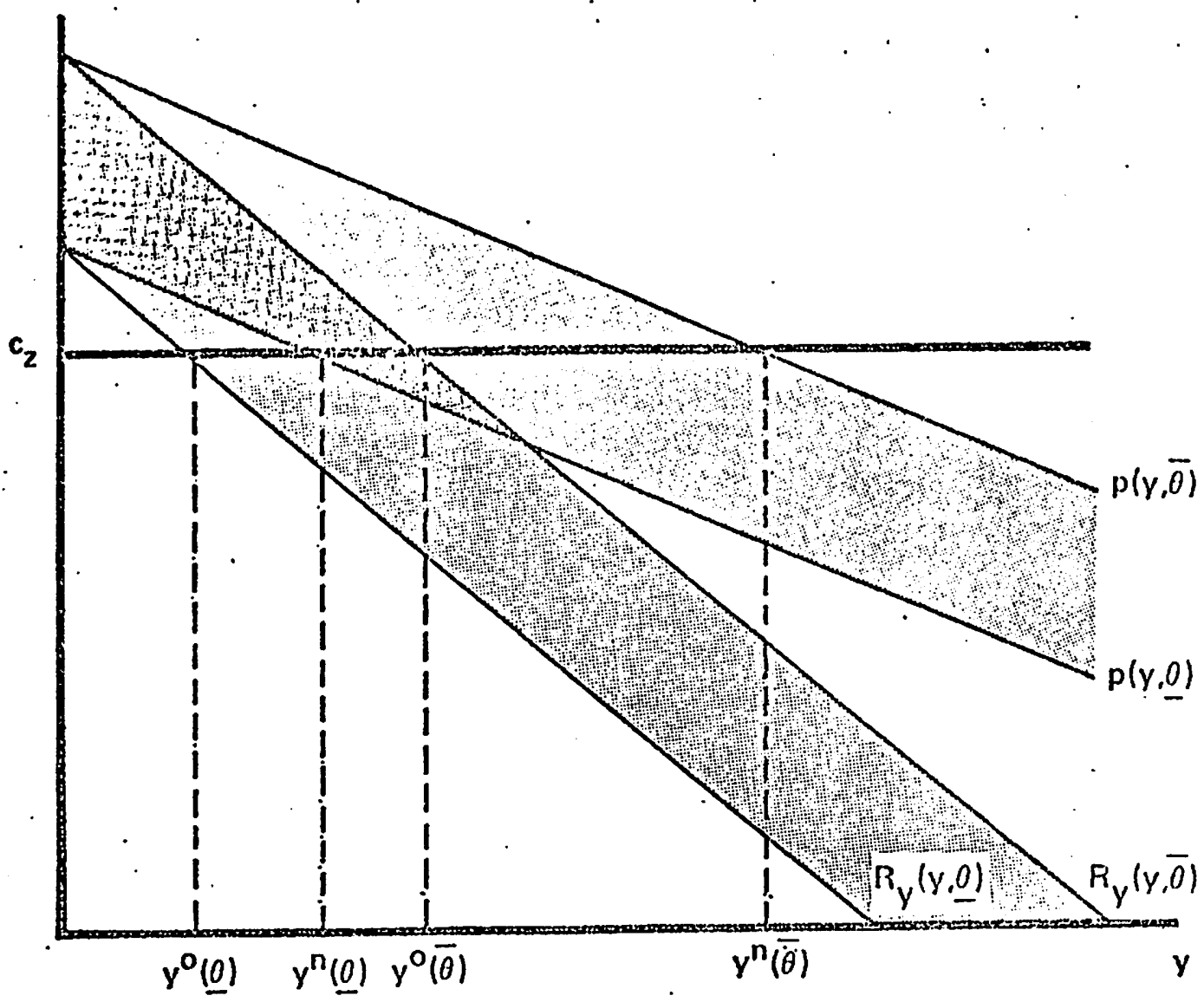

Figure 2(a)

$E\left[M R^{n}\right]$ in thicik line: $c_{z} K^{n} \bar{K}_{M}$

$E\left[M R^{\circ}\right]$ in thin line: $c_{2} \underline{K}^{\circ} \bar{K}^{O} M$

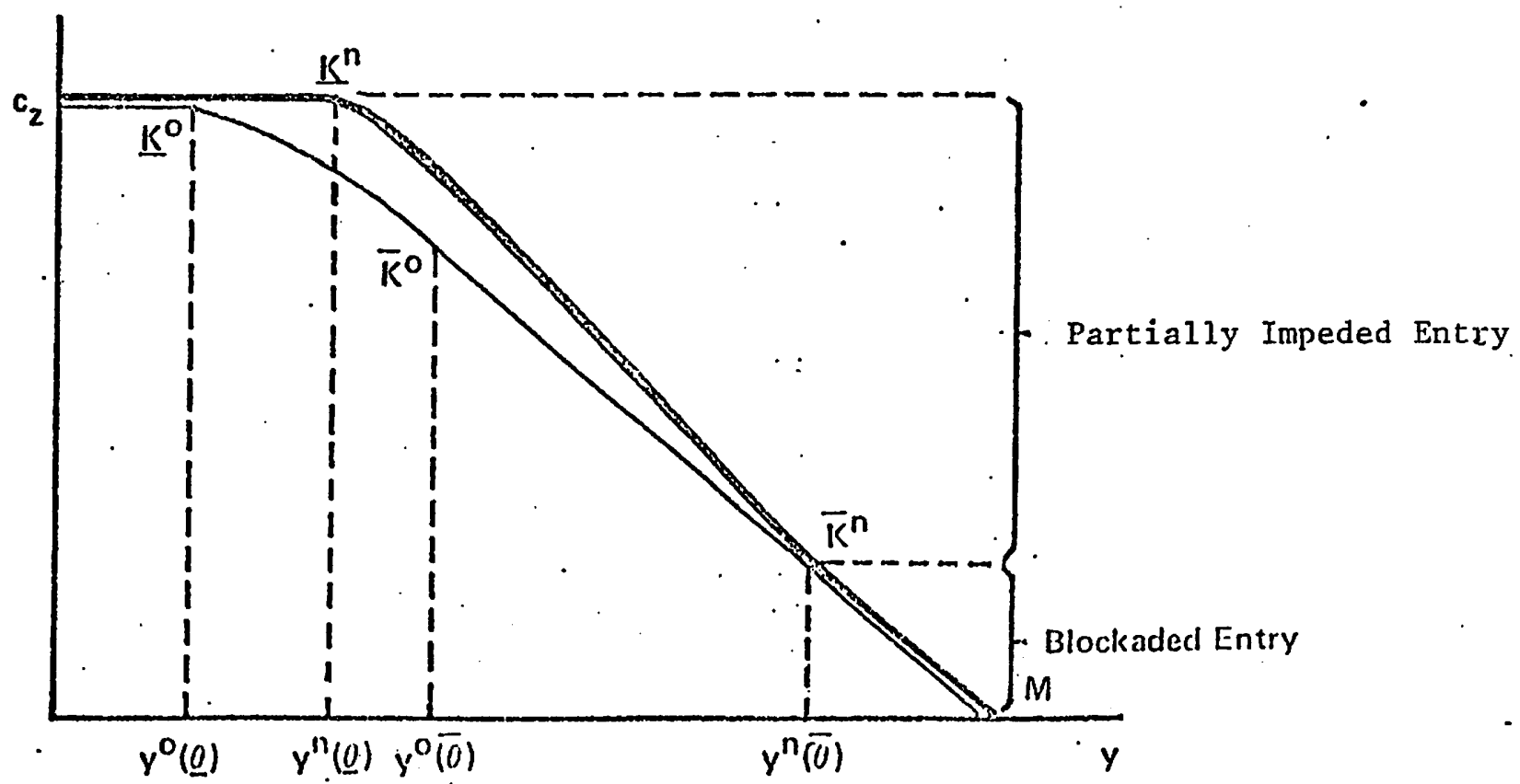

Figure $2(b)$ 


$$
p^{n}(y, \theta) \equiv p(y+z, \theta)= \begin{cases}c_{z} & \text { if } y \leq y^{n}(\theta) \\ p(y, \theta) & \text { if } y \geq y^{n}(\theta)\end{cases}
$$

This follows immediately from (16) and (17).

The difference between the primitive demand price distribution $p(y, \theta)$ and the entry-constrained demand price distribution $p^{n}(y, \theta)$ emphasizes the discipline that the potential entrants impose on the incumbent. Faced with $p^{n}(y, \theta)$ given by (18), the incumbent's expected profit can be expressed as

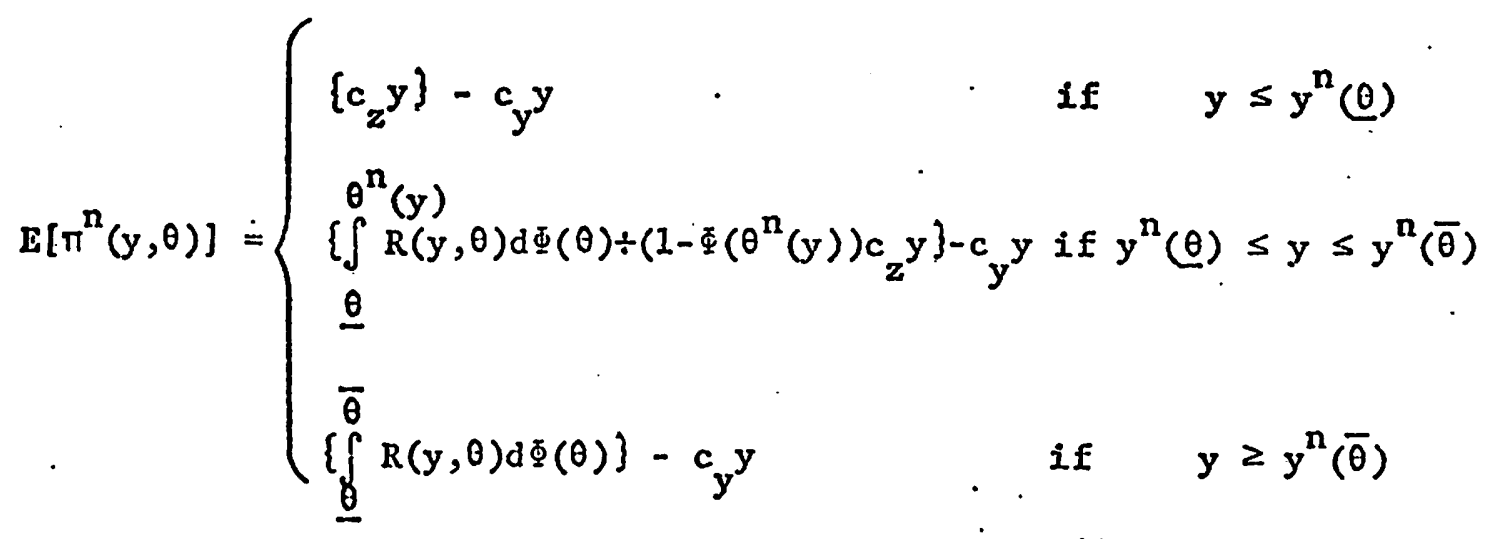

where $\theta^{n}(y)$ is defined above and satisfied $y^{n}\left(\theta^{n}(y)\right)=y$. Maximizing (19) with respect to y yields the necessary and sufficient condition 12

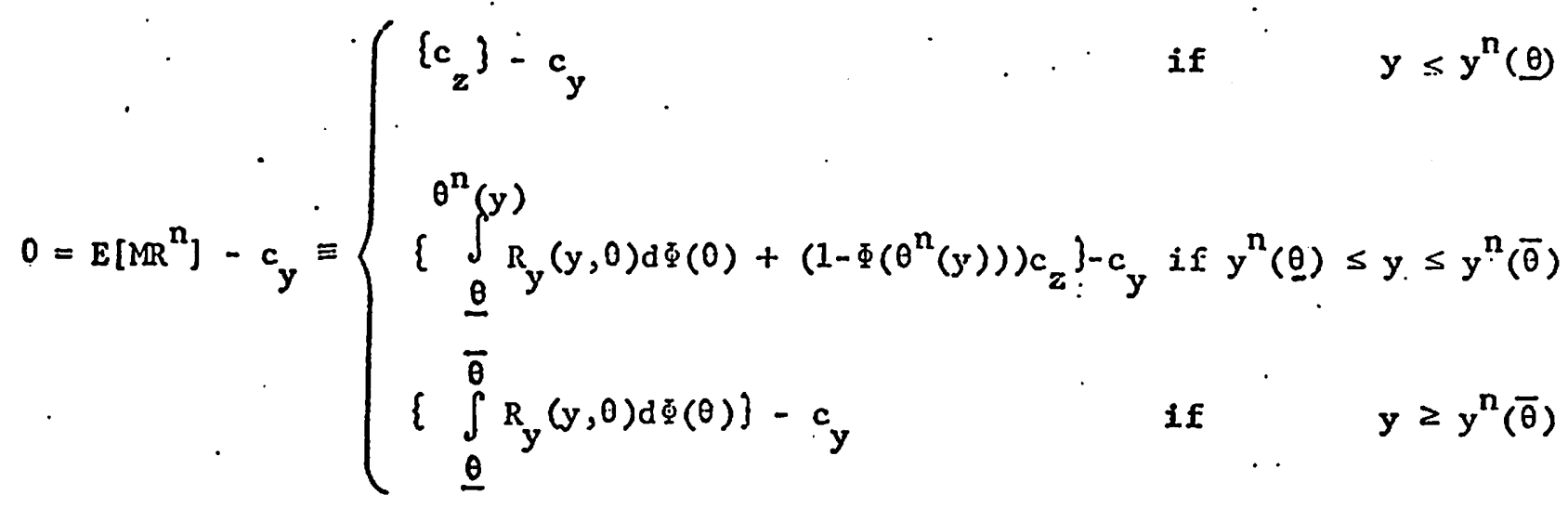


This says that the entry-constrained optimum must equate the effective expected marginal revenue $E\left[\mathrm{MR}^{\mathrm{n}}\right]$ (the bracketed $\{\cdot\}$ terms in (20) with the marginal cost $c \cdot$

In comparing the entry-constrained optimum condition in (20) with the entry-free optimum in (11), note that they are very similar, except for one important but subtle difference. The $E\left[\mathbb{R}^{\mathrm{n}}\right]$ terms in (20) are defined for the range of $\mathrm{y}$ with respect to $\mathrm{y}^{\mathrm{n}}(\theta)$ whereas the $E\left[\mathrm{MR}^{\circ}\right]$ terms in (11) are defined for the range of $y$ with respect to $y^{0}(\theta)$. This difference becomes more transparent in Figure $2(b)$ where we superimpose the $E\left[\mathbb{R}^{\mathrm{n}}\right]$ schedule (given by the thick curve $\left.c_{2} \underline{K}^{n} \bar{K}^{n} M\right)$ on the $E\left[M_{R}^{0}\right]$ schedule taken from Figure $1(b)$. It can be easily checked ${ }^{13}$ that the entire $E\left[\mathbb{R}^{n}\right]$ schedule is continuous and smooth at $\underline{\mathrm{K}}^{\mathrm{n}}$ and $\overline{\mathrm{K}}^{\mathrm{n}}$. From (11) and (20) we get

$$
E\left[\mathbb{R R}^{n}\right]-E\left[M^{\circ}\right]=\int_{\theta^{n}(y)}^{\theta^{o}(y)} R_{y}(y, \theta) d \bar{\Phi}(\theta)+\left\{\Phi\left[\theta^{o}(y)\right]-\bar{\Phi}\left[\theta^{n}(y)\right]\right\} \geq 0 \text { al1 y }
$$

since $\theta^{0}(y) \geq \theta^{\mathrm{n}}(y)$ all $y$. In the region $\mathrm{y}^{\mathrm{o}}(\underline{\theta})<\mathrm{y}<\mathrm{y}^{\mathrm{n}}(\bar{\theta})$, we have $E\left[\mathrm{MR}^{\mathrm{n}}\right]>E\left[\mathrm{MR}^{\mathrm{o}}\right]$ whereas elsewhere we have $E\left[\mathrm{MR}^{\mathrm{n}}\right]=E\left[\mathrm{MR}^{\mathrm{o}}\right]$.

Using Figure 2(b), we shall now compare the entry-free optimum (without potential entry) with the entry-constrained optinum (with potential entry). In order not to further cluster the diagram, the insertion of the horizontal $c_{y}\left(<c_{z}\right)$ line is left to the reader. Let $y *$ define the entry-free optimum (which satisfies (11) or the intersection between $c_{y}$ and the $E\left[\mathbb{R}^{\circ}\right]$ schedule) and $y^{* *}$ define the entry-constrained optimum (which satisfies (20) or the intersection between $c_{y}$ and the $E\left[M^{n}\right]$ schedule).

Since $E\left[\mathbb{R}^{\mathrm{n}}\right] \geq E\left[\mathbb{R}^{\circ}\right],{ }^{14}$ it is always true that $\mathrm{y}^{* *} \geq \mathrm{y}^{*}$. In other words, the presence of an ex post contestable market causes the incumbent's ex ante production to be at least equal to or larger than when there is no potential entrants. This is to be expected since the presence of an ex post contestable 
market tends to induce the monopolist to behave "more competitively" by expanding his ex ante production level.

Second, since $c_{y}<c_{z}$, the first line of $(20)$ can never hold, so that $y^{* *}$. must. lie in the region $y^{* *}>y^{n}(\underline{\theta})$. Consequently, for $\theta \varepsilon\left[\underline{\theta}, \theta^{n}\left(y^{*} *\right)\right]$, where $\theta^{n}\left(y^{* *}\right)$ is defined by $y^{n}\left(\theta^{n}\left(y^{* *}\right)=y^{* *}\right.$, we have (from $\left.(17)\right) z=0$. Hence, with potential ex post entry, the incumbent's ex ante production will always be high enough such that ex post entry will never occur for the low states of demand: $\theta \in\left[\theta, \theta^{n}\left(y^{*} *\right)\right]$. Entry, if it ever occurs, does so only in the better states: $\theta \varepsilon\left(\theta^{n}\left(y^{* *}\right), \bar{\theta}\right]$. This emphasizes the point that while entrants, being late-comers, do not have the opportunity to produce ex ante, they nevertheless have the flexibility of choosing to enter the market only in the better states of demand.

Finally, as Figure 2(b) clearly reveals, there are only two types of optimal strategies that the incumbent may pursue in reaction to potential entry. The first occurs whenever $c_{y}$ is small and lies between $\bar{K}^{n}$ and $M$. In this case the incumbent's optimal strategy is to leave ex ante output unchanged (i.e. $y * *=y^{*}$ ).

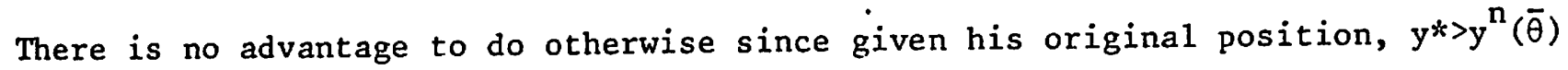
is such that the probability of entry is zero (i.e. entry $z=0$ for all $\theta$ ). Thus, even if there are potential entrants, there is no effective threat of actual entry since the original entry-free optimum $y^{*}$ is already large enough to make entry unprofitable for any state of demand $\theta$. This strategy is analogous to Bain's blockaded entry.

The other strategy occurs when $c_{y}$ lies between $\underline{k}^{n}$ and $\bar{K}^{n}$. In this case, the incumbent's optimal strategy is to expand $y^{*}$ to $y^{* *}$, and hence decrease the probability of entry from $p\left[\theta \geq \theta^{n}\left(y^{*}\right)\right]$ to $p\left[\theta \geq \theta^{n}\left(y^{* *}\right)\right]$. However since $y^{* *<y^{n}}(\bar{\theta})$ we have that $\theta^{n}\left(y^{* *}\right)<\bar{\theta}$, so that the probability of entry is $p\left[\theta>\theta^{n}\left(y^{*}\right)\right]>0$, in other words, the optimal strategy does not completely block entry (i.e., in all states); there are some (better) states, $\theta \varepsilon\left(\theta^{n}\left(y^{* *}\right), \bar{\theta}\right]$, where entry will occur. It should be clear that the solution in our model gives 
the "optimally impeded" entry; it does not pay the firm to reduce the probability of entry to zero even though it can do so. This is in contrast with what we think of when we talk about ineffectively-impeded entry, (see Bain) where the firm would have liked to impede entry even further, but could not do so effectively.

. What is a most interesting result of our model is the absence of the "limit output" (price), or effectively-impedod entzy, as a possible optimal strategy. If it pays the firm to reduce (the probability of) entry (increase y) it will do so, but not to such an extent that entry will be totally blocked (in all states). While this result seens rather surprising, it can, on second thought, be easily explained. If we recall from the non-stochastic literature, the optimality of the "limit-output" strategy arises because of a "corner solution" (see e.g., Osborne (1973)). In our stochastic model, however, where $\theta$ is assumed to be a continuous random variable defined by a continuous probability density $\mathrm{d} \Phi(\theta)$, all corner solutions vanish since this assumption makes the $E\left[\mathrm{MR}^{\mathrm{n}}\right]$ functici] smooth, as shown in Figure 2(b). Consequently, it is not surprising that our model does not generate the case of effectively-impeded entry as a possible optimal outcome.

From the standpoint of theoretical analysis, the continuous probability density function specified in (2) is clearly advantageous both in its generality and analytical convenience. It may, however, also be a

abstraction from the real world where agents more often than not perceive probabilistic events in discrete terms. In the next section, therefore, we shall reexamine the model when we consider a discrete-probability distribution. The resulting model not only recovers the "limit-output" result as a possible optimal outcome, it also generates a class of outcomes that is richer (contains more strategies) than Bain's initial classification.

Before we conclude this section, however, we shall examine the effects of changes in various parameters. 
Using the result of the previous section, and noting the $E\left[M R^{n}\right]$ curve is similar to the $E\left[\mathrm{MR}^{\circ}\right]$ curve (except for the boundary reference points) we get that

$$
\mathrm{dE}\left[\mathrm{MR}^{\mathrm{n}}\right] / \mathrm{dc} z \geq 0 \text { and } \mathrm{dE}\left[\mathrm{MR}^{\mathrm{n}}\right] / \mathrm{d} \gamma \leq 0
$$

in other words, an increase in ex post cost will shift the expected marginal revenue curve up, whereas an increase in uncertainty (assuming $R_{y}(y, \theta)$ is concave in $\theta$, or else assuming first order stochastic dominance) will shift it down. Thus, we conclude

$$
\begin{aligned}
& d y^{* *} / d c_{y} \leq 0, d P\left[\theta>\theta^{n}\left(y^{* *}\right)\right] / d c_{y} \geq 0, d E\left(z^{* *}\right) / d c_{y} \geq 0 \\
& d y^{* *} / d c_{z} \geq 0, d P\left[\theta>\theta^{n}\left(y^{* *}\right)\right] / d c_{z} \leq 0, d E\left(z^{* *}\right) / d c_{z} \leq 0 \\
& d y^{* *} / d \gamma \leq 0, \quad d P\left[\theta>\theta^{n}\left(y^{* *}\right)\right] / d c_{z} \geq 0, d E\left(z^{* *}\right) / d \gamma \geq 0
\end{aligned}
$$

where $P\left[\theta>\theta^{n}(y * *)\right]$ is the probability of entry and $E\left[z^{* *}\right]$ is the equilibrium level of expected ex post production.

An increase in the efficiency of ex ante production (decreasing $c_{y}$ ) will, therefore, increase the incumbent's pre-commitment and consequently, will reduce the probability of entry and the level of expected ex post production. An increase in the efficiency of ex post production (decreasing $c_{z}$ ) will have the opposite effect. Thus, as ex ante production becomes relatively more efficient, the market becomes "less contestable".

Furthermore, as uncertainty increases, the incumbent's pre-commitment decreases and the probability of entry and the level of expected ex post production increases. Thus, greater uncertainty will make the market "more contestable". This, of course, also suggests that the scope for entry deterrence strategies on the part of the incumbent is reduced; the advantage of the first move is more limited. In cases like this, it seems that there is room for activities aimed at the improvement of the information about the possible states 
of the world. For example, the firm will have an incentive to invest money in trying to obtain predictors for $\theta$, say by looking at variables correlated with it, or generally by engaging in market research which generates ("better") conditional distributions for $\theta$.

IV A DISCRETE-PROBABILITY FOLEL

Consider the random variable $\theta$ which takes on discrete values $[\underline{\theta}, \underline{\theta}+\delta, \ldots, \underline{\theta}+(\mathrm{N}-1) \delta, \bar{\theta}]$ (where $\delta=(\bar{\theta}-\underline{\theta}) / \mathrm{N}$ ) with probabilities $\left[\phi_{1}, \phi_{2}, \ldots \phi_{N}, \phi_{N+1}\right]$; and with $\sum_{i=1}^{N+1} \phi_{i}=1$. Then as $N \rightarrow \infty$, the above random variable and the probability distribution approaches the continuous form given by $\phi(\theta)$. Conversely, as $N \rightarrow 1$, we get the other extreme form where $\theta$ takes on the discrete values

$$
[\underline{\theta}, \bar{\theta}] \text { with probabilities }[\phi,(1-\phi)]
$$

so that $\underline{\theta}$ and $\bar{\theta}$ can now be interpreted as the low and high states of demand respectively.

In the remainder of this section, it sufficies to explicitly model the limiting case when $\theta$ is binomially distributed as in (24). The contrast between this and the other extreme case when $\theta$ has a continuous density function as in (2) will make it transparent as to how the model is affected in the intermediate cases when $\theta$ takes on more than two discrete values.

The route that we follow is to replace $\phi(\theta)$ with (24) and then derive and compare the entry-free and the entry-constrained optima. It is easily verified that given the binomial distribution (24), the entry-free optimum condition (11) is now modified to

$$
O=E\left[\operatorname{MR}^{0}\right]-c_{y} \equiv \begin{cases}\left\{c_{z}\right\}-c_{y} & \text { if } y \leq y^{0}(\theta) \\ \left\{\phi R_{y}(y, \underline{\theta})+(1-\phi) c_{z}\right\}-c_{y} & \text { if } y^{0}(\underline{\theta}) \leq y \leq y^{0}(\bar{\theta}) \\ \left\{\phi R_{y}(y, \underline{\theta})+(1-\phi) R_{y}(y, \bar{\theta})\right\}-c_{y} & \text { if } y^{0}(\bar{\theta}) \leq y\end{cases}
$$


and the entry-constrained optimum condition (20) now becomes

$$
0=E\left[M R^{n}\right]-c_{y} \equiv \begin{cases}\left\{c_{z}\right\}-c_{y} & \text { if } y \leq y^{n}(\underline{\theta}) \\ \left\{\phi R_{y}(y, \underline{\theta})+(1-\phi) c_{z}\right\}-c_{y} & \text { if } y^{n}\left(\underline{\theta} \leq y \leq y^{n}(\bar{\theta})\right. \\ \left\{\phi R_{y}(y, \underline{\theta})+(1-\phi) R_{y}(y, \bar{\theta})\right\}-c_{y} & \text { if } y^{n}(\bar{\theta}) \leq y\end{cases}
$$

where $y^{0}(\theta)$ and $y^{n}(\theta)$ are as previously defined (see also Figure $3(a)$ ). Comparing (11)' and (20)', observe that the $\operatorname{E}\left[\mathrm{MR}^{\circ}\right]$ terms (bracketed $\{\cdot\}$ in (11)') and the $E\left[M R^{n}\right]$ terms (bracketed $\{\cdot\}$ in $(20)^{\prime}$ ) are the same except for one important difference: The optimum conditions for each line in (11)' and (20)' hold for different regions of $y$ since $y^{0}(\theta) \neq y^{n}(\theta)$. This becomes more transparent in Figure $3(\mathrm{~b})$ where the $E\left[\mathrm{MR}^{\circ}\right]$ schedule appears as the thin line segments $c_{z} \underline{K}^{o}, \underline{K}^{\circ} \bar{K}^{\circ}$ and $\bar{K}^{\circ} M$ with kinks occurring at $\mathrm{y}^{\circ}(\underline{\theta})$ and $\mathrm{y}^{\circ}(\bar{\theta})$ whereas the $E\left[M^{n}\right]$ schedule consists of the discontinuous thick line segments $c_{2} \underline{K}^{n}, L^{n} \bar{K}^{n}$ and $\bar{L}^{n} M$ with discontinuities at $\mathrm{y}^{\mathrm{n}}(\underline{\theta})$ and $\mathrm{y}^{\mathrm{n}}(\bar{\theta})$.

The two polar models in Figures $3(\mathrm{~b})$ and $2(\mathrm{~b})$ provide an interesting contrast. In Figure $3(\mathrm{~b})$ the $E\left[\mathbb{R}^{\circ}\right]$ and $E\left[\mathbb{R}^{\mathrm{n}}\right]$ schedules contain kinks and discontinuities respectively; whereas in Figure $2(\mathrm{~b})$ both these schedules are continuous and smooth. Comparing the two figures, it can be easily shown how Figure 3(b) will converge toward Figure $2(\mathrm{~b})$ as we admit an increasing number of discrete states. The reader is encouraged to check that as the number of discrete states increases, the $E\left[M^{\circ}\right.$ ] segments $\underline{K}^{0} \bar{K}^{\circ}$ in Figure $3(b)$ will have an increasing number of kinks until in the limit it approaches the smooth concave surface $\underline{K}^{\circ} \overline{\mathrm{K}}^{\mathrm{O}}$ in Figure $2(\mathrm{~b})$. Furthermore, the $E\left[\mathbb{R}^{n}\right]$ segment $\underline{L}^{n^{-n}}$ in Figure $3(b)$ will rotate clockwise while being disjoined to contain an increasing number of discontinuities; but with the gap in each discontinuity (including the gaps $\underline{K}^{n} \underline{L}^{n}$ and $\bar{K}^{n} \bar{L}^{n}$ ) becoming smaller as $\mathrm{N}$ becomes large. In the limit, all gaps are closed and the segment $\underline{L}^{\mathrm{n}} \overline{\mathrm{K}}^{\mathrm{n}}$ in Figure $3(\mathrm{~b})$ converges to become the smooth $\underline{k}^{n} \overline{\mathrm{K}}^{\mathrm{n}}$ curve in Figure $2(\mathrm{~b})$. . 


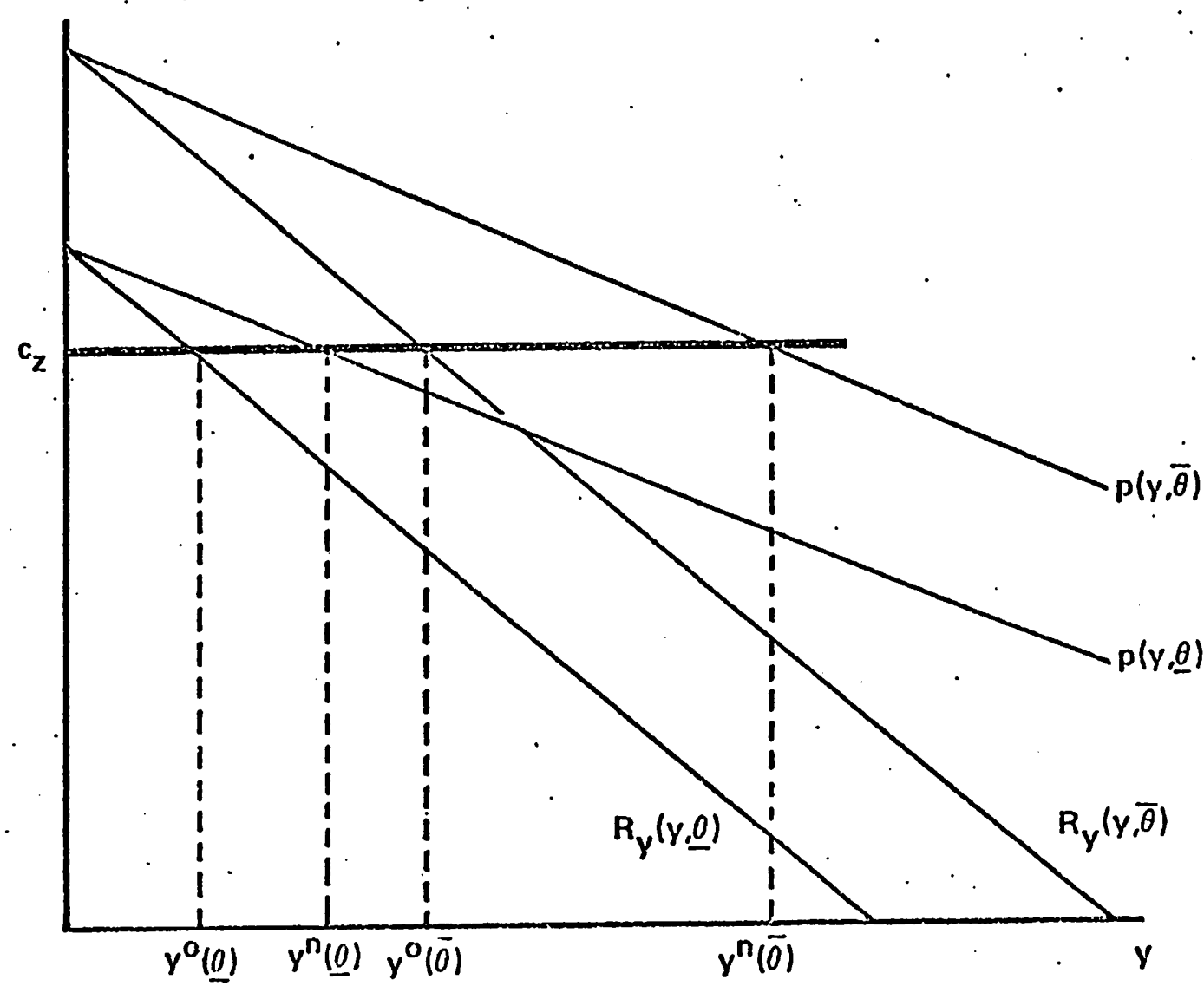

Figure 3(a)

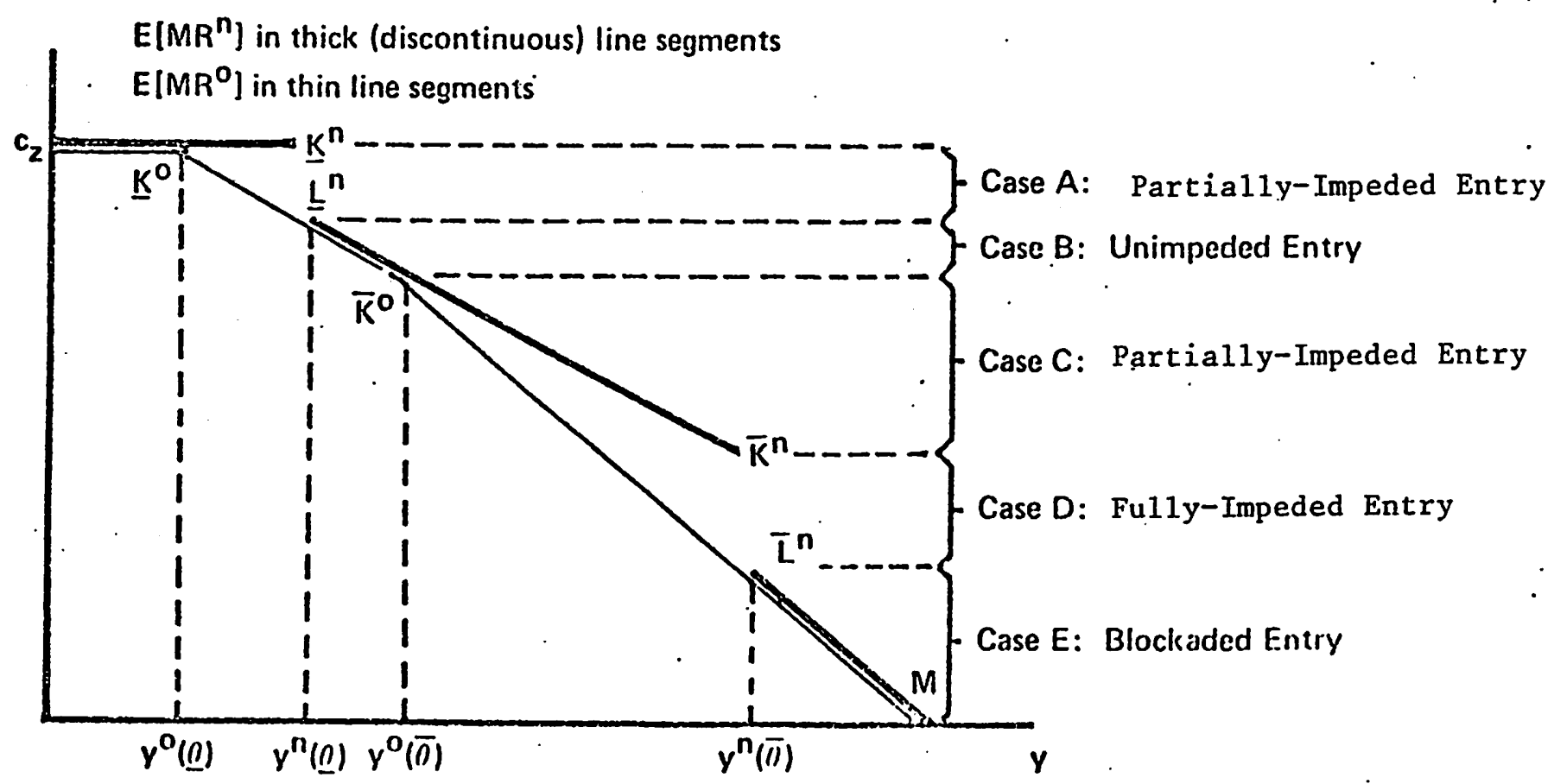

Figure $3(!)$ 
Thus, except for the limiting case of the continuous probability density, $E\left[M^{\circ}\right]$ and $E\left[\mathbb{R}^{n}\right]$ will always exhibit kinks and discontinuities. Furthermore, since the results that we find most interesting are tinose associated with these kinks and discontinuities, there is essentially no loss of generality in using the binomial probability distribution to demonstrate our results. The implications that are derived from it are perfectly generalizable to all other higher dimensional discrete multinomial probability distributions.

The implications of the discrete-probability model can be read off easily from Figure 3(b). Compared to the continuous-probability model in Figure 2(b), it contains a far richer set of optimal strategies.

To see this, define as before $y^{*}$ and $y^{* *}$ to be, respectively, the entry-free optimum (where $c_{y}$ intersects $E\left[\mathrm{MR}^{\circ}\right]$ ) and the entry-constrained optimum (where $c_{y}$ intersects $E\left[M R^{n}\right]$ ). Then as we vary $c_{y}$ (left to the reader) downward from the position $c_{y}=c_{z}$ in Figure $3(b)$, we will have the following outcomes:

Case A: Partially impeded entry This happens when the incumbent's cost advantage is small so that it is preferable to allow entry. In our stochastic model this happens when $c_{y}\left(<c_{z}\right)$ lies in the gap $\underline{K}^{n} \underline{L}^{n}$ so that $y^{0}(\underline{\theta})<y *<y^{0}(\bar{\theta})$ and $y^{*}<y^{* *}=y^{n}(\underline{\theta})<y^{n}(\bar{\theta})$. Without potential entry, the monopolist's $y^{*}$ will entertain ex post production adjustment in the good state (since $y^{*}<\mathrm{y}^{0}(\bar{\theta})$ ) but not in the bad state (since $\left.\mathrm{y}^{0}(\underline{\theta})<\mathrm{y}^{*}\right)$. In the presence of potential entry, it expands $y^{*}$ to $y^{* *}=y^{n}(\underline{\theta})$ so that entry will not occur in the bad state $\underline{\theta}$; but entry will be permitted in the good state $\bar{\theta}$ since $y^{* *}=y^{n}(\underline{\theta})<y^{n}(\bar{\theta})$. Case B: Unimpeded entry This case, which Bain overlooked, happens when $c_{y}$ cuts the segment $\underline{L}^{n} \bar{K}^{0}$ where both $E\left[M R^{\circ}\right]$ and $E\left[M R^{n}\right]$ coincide. Thus, we have $y^{*}=y^{* *}$ and $y^{n}(\underline{\theta})<y^{*}=y^{* *}<y^{0}(\ddot{\theta})$. Because $y^{*}=y^{* *}$, the presence of potential entry does not alter the incumbent's entry-free optimum $\mathrm{y}^{*}$. This is clearly an interesting strategy given that the status quo behaviour is maintained despite the realizable 
threat of entry in the good state ( since $y^{n}(\underline{\theta})<y^{*}<y^{n}(\bar{\theta})$ ). It is important to differentiate between this and the status quo behaviour embodied in the blockaded entry case (to be discussed later under Case E). Therein, it will be shown that the monopolist's status quo behaviour arises simply because the threat of entry is never realizable since his original entry-free optimum $y^{*}$ is already so high as to force all possible prices below $c_{z}$. Consequently, there is no need to expand $y *$ since no profitable entry will ever take place. In this case B, however, the threat of entry is clearly realizable in the good state, but, in spite of this, his output is unchanged. The reason is that in the segment $\underline{L}^{n} \bar{K}^{\circ}$, the effective expected marginal revenue is unaffected by the presence of potential entry $\left(E\left[\mathbb{M R}^{\circ}\right]=E\left[\mathbb{R}^{n}\right]\right)$.

Case C: Partially-Impeded entry (again): This case occurs whenever $c_{y}$ falls between $\overline{\mathrm{K}}^{\mathrm{o}}$ and $\overline{\mathrm{K}}^{\mathrm{n}}$. Without potential entry, the optimum $\mathrm{y} *$ lies in the region $\mathrm{y}^{*}>\mathrm{y}^{0}(\bar{\theta})>\mathrm{y}^{0}(\underline{\theta})$ which implies no ex post production adjustment for all states of demand. However, with potential entry, $y^{*}$ is expanded to $y^{* *}$. But, because $y^{n}(\underline{\theta})<y^{* *}<y^{n}(\bar{\theta})$ such expansion will still accommodate entry in the good state. This case is quite similar to Case A except for one difference. In Case $A$, the entry-free optimum $y^{*}$ lies in the region $y^{0}(\underline{\theta})<y^{*}<y^{0}(\bar{\theta})$ so that it entertains ex post production adjustment in the good state; whereas the entry-free optimum in this case lies in the region $y^{*}>y^{0}(\bar{\theta})>y^{0}(\underline{\theta})$ implying no ex post adjustment for all states of demand.

Case D: Fully-Impeded Entry This occurs when $c_{y} \dot{f a l l s}$ betw-en $\bar{K}^{n}$ and $\overline{\mathrm{L}}^{\mathrm{n}}$. The entry-free optimum $y^{*}$ lies in the region $y^{*}>y^{0}(\bar{\theta})>y^{0}(\underline{\theta})$ implying there is no ex post production adjustment for a11 $\theta$. In the presence of potential entry, $y^{*}$ is expanded to $y^{* *}=y^{n}(\bar{\theta})$ which totally blocks entry for all states of ciemand. This is the uncertainty "analogue" of the classic "limit-output" or "limit-price" model. 
Case E: Blockaded Entry (Bain's terminology). This happens when $c_{y}$ lies the segment $\bar{L}^{n} M$. He:ce, the monopolist (in the absence of potential entry) takes advantage of the low $c_{y}$ to produce a high level of $y^{*}$ and, because of large marginal adjustment cost $\left(c_{z}-c_{y}\right)$, does not indulge in ex post production since $y^{*}>y^{0}(\bar{\theta})$. Furthermore, because $y^{*}>y^{n}(\bar{\theta})$, there is no realizable threat of entry since it is unprofitable to enter in all states of demand. Consequently there is no need to alter its initial optimum (i.e., $y^{*}=y^{* *}$ ) even if there are potential entrants; entry is automatically blockaded.

Case A to E represent the largest posstble set of descriptive outcomes. The reader is also encouraged to check that by varying $c_{z}$ of the parameters of the distribution function, we get the comparative static results obtained above. Finally, it is interesting to relate our set of possible outcomes, in this last model, to the class of possible outcomes in the noastochastic entry deterrence 1iterature. For example, Bain [1956] provides a discussion of blockaded entry, effectively impeded entry and ineffectively impeded entry. These cases bear some but not an exact resemblance to our outcomes. In our model, we cannot speak of effectively or ineffectively impeded entry since entry impediment is only probabilistic, and, more importantly, the probability of entry is optimally chosen (ex ante) by the incumbent. Furthermore, it should be noted that our model is able to generate a larger and richer set of outcomes compared to Bain's classification. 
V. Conclusion

In this paper we present a model of a market which is ex post contestable. We show that in a market characterized by uncertainty a firm will face a tradeoff between efficiency and flexibility and in general will make some precommitments, taking advantage of efficient ex ante technologies. Its cost structure will thus, partially, reflect the effects of uncertainty on the choice of techniques.

We show that in the face of potential entry, when the market is ex post contestable, the incumbent will increase his precommitments and in doing so will decrease the probability of entry. Precomitment will thus be used to affect the probability of entry or the degree of market contestability. The extent to which precommitments will be used to affect entry probabilities is shown to depend on the efficiency of ex ante production, adjustment costs and the degree of uncertainty. In particular, we show that the market becones (effectively) "more contestable" as relative efficiency of ex post production increases (lower adjustment costs) and as market conditions become more uncertain.

Finally, we show that the nature of the possible outcomes depends crucially on the nature of the probability distribution of the demand functicin. Whereas continuous density functions exclude the. possibility of "Iimit output" outcomes, discrete probability functions give rise to a much richer set of possible outcomes including blockaded entry, fully, partially and unimpeded entry. 
1. For a discussion of the theory of contestable markets see in addition references in Baumol Panzar and Willig [1982] and survey articles by Bailey and Friedlaender [1982], Spence [1983].

2. For a discussion of the role of irreversibility in the context of deterrence in general see Schelling [1960] and for applications to entry deterrence see for example Spence [1977], Salop [1979], Dixit $[1979,1980]$, Spulber [1981].

3. For a discussion of limit-output strategies see Bain [1956], Kamien and Schwartz [1971, 1975] Gaskins [1971], Flaherty [1981], Osborne [1973].

4. This could be compared with Bain's classification of blockades, effectively and ineffectively impeded entry, see Bain [1956]. In our mode, however, the degree to thich entry is impeded is random (i.e., probabilistic) and furthermore, this probability is optimally chosen.

5. See for example Hicks [1973], Appelbaum and Harris [1977]

6: The sufficiency condition is ensured because of the strict concavity of $R(q, \theta)$ in $q$.

7. The curve $\underline{\mathrm{K}}^{\mathrm{o}} \overline{\mathrm{K}}^{\mathrm{o}}$ is described by $\mathrm{s}^{\mathrm{o}}(\mathrm{y}) \equiv \int_{\underline{\theta}}^{\theta^{\circ}(\mathrm{y})} \mathrm{R}_{\mathrm{y}}(\mathrm{y}, \theta) \mathrm{d} \Phi(\theta)+\left(1-\Phi\left(\theta^{\circ}(\mathrm{y})\right)\right) \mathrm{c}_{z}$. This curve is smooth at $\underline{\mathrm{K}}^{\mathrm{o}}$ and $\overline{\mathrm{K}}^{\mathrm{o}}$ since as $\mathrm{y} \rightarrow \mathrm{y}(\underline{\theta})$, we have $\theta^{\mathrm{o}}(\mathrm{y}) \rightarrow \underline{\theta}$ and $S^{0}(y)+c_{z}$; and as $y \rightarrow y^{\circ}(\bar{\theta})$, we have $\theta^{0}(y)+\bar{\theta}$ and $S^{\circ}(y)+E\left[R_{y}(y, \theta)\right] . \quad S^{\circ}(y)$ is ziso strictly concave since $s_{y}^{o}=\int^{\theta^{\circ}(y)} R_{j y}(y, \theta) d \Phi(\theta)<0$ and $s_{y y}^{o}=\frac{\partial \theta^{\circ}(y)}{\partial y} R_{y y}\left(y, \theta^{\circ}(y)\right)<0$.

8. Even for the linear demand curve, $E\left[R_{y}(y, \theta)\right]$ is in general nonlinear since for those $\theta$ where $\mathrm{R}_{\mathrm{y}}(\mathrm{y}, \theta)<0$, it is desirable to dispose of some $\mathrm{y}$. In drawing the segment $\overline{\mathrm{K}}^{\mathrm{o}} \mathrm{M}$ as 1 inear, we have purposely chosen to ignore the disposal problem since introducing it only complicates the analysis and adds nothing to the results of this paper.

9. See Hanoch and Levi (1969), Hadar and Russel (1969).

10. For models where entrants have incomplete information about the incumbent's cost structure, see Milgrom and Roberts [1982], and Mathews and Mirman [1981]. 
11. Since $c_{z}$ is constant, there is no differentiation between $z$ produced by the incumbent or the entrants in the ex post zero-profit equilibrium.

12. Sufficiency is ensured by the strict concavity of $R(q, \theta)$ in $q$.

13. The curve $\underline{K}^{n} \bar{K}^{n}$ is described by $s^{n}(y) \equiv \int_{\theta}^{\theta^{n}(y)} R_{y}(y, \theta) d \Phi(\theta)+\left(1-\phi\left(\theta^{n}(y)\right)\right) c$. This curve is continuous and smooth $\underline{\theta}^{\frac{\theta}{k}} \underline{\mathrm{K}}^{\mathrm{n}}$ and $\overline{\mathrm{K}}^{\mathrm{n}}$ since as $\mathrm{y} \rightarrow \mathrm{y}^{\mathrm{n}}(\underline{\theta})$ we have $\theta^{n}(y)+\theta$ and $s^{n}(y)+c_{z}$; whereas as $y \rightarrow y^{n}(\bar{\theta})$. we have $\theta^{n}(y)+\bar{\theta}$ and $s^{n}(y)+E\left[R_{y}(y, \theta)\right]$.

14. Since the area under the $E\left[M R^{\circ}\right]\left(\leq E\left[M R^{n}\right]\right)$ schedule has been pointed out to be an underestimation of the expected revenue in the case of no potential entry, one should not be tempted to draw the implication that expected revenue in the case of potential entry exceeds that when there is no potential entry. This implication is obviously false. 


\section{REFERENCES}

APPELBAUM, E. and HARRIS, R.J., (1977), "Estimating Technology in An Intertemporal Framework; A Neo-Austrian Approach", Review of.Economics and Statistics.

BAIN, J.S. (1956), Barriers to New Competition, Cambridge: Harvard University Press.

Bailey, E.E., and Friedlaender, A.F., (1982), "Market Structure and Multiproduct Industries", Journal of Economic Literature, 20, 1024-1048.

BARON, D. (1971), "Demand Uncertainty in Imperfect Competition," International Economic Review, 12, 196-208.

(1970), "Price Uncertainty, Utility, and Industry Equilibrium in Pure Competition," International Economic Review, 11, 463-480.

BAUMOL, W.J., PANZAR, J.C. and WILLIG, R.D. [1982], Contestable Markets and the Theory of Industry Structure, New York: Harcourt, Brace Jovanovich Inc.

DIXIT, A. (1979), "A Model of Duopoly Suggesting a Theory of Entry Barriers," Bell Journal of Economics, 10, 20-32.

(1980), "The Role of Investment in Entry-Deterrence," Economic Journal, 90, 95-106.

EPSTEIN, L. (1978), "Production Flexibility and the Behavior of the Competitive Firm Under Price Uncertainty," Review of Economic Studies, 45, 251-262.

FLAHERTY, M.T. (1980), "Dynamic Limit Pricing, Barriers to Entry, and Rational Firms," Journal of Economic Theory, 23, 160-182.

GASKINS, D. (1971), "Optimal Limit Pricing: Optimal Pricing Under Threat of Entry," Journal of Economic Theory, 2, 306-322.

HADAR, R.R., and RUSSEL, W.R., (1969), "Rules for Ordering Uncertain Prospects," American Economic Review.

HANOCH, G. and LEVI, H.,[1969] "The Efficiency Analysis of Choice Involving Risk" Review of Economic Studies.

HARTMAN, R. (1976), "Factor Demand with Output Price Uncertainty," American Economic Review, 66, 675-681.

HICKS, J.R., (1973), Capital and Time London, Oxford University Press.

KAMIEN, M.I. and SCHWARTZ, N.L. (1971), "Limit Pricing and Uncertain Entry," Econometrica, 39, 441-454.

(1975) "Cournot 01igopoly with Uncertain Entry," Review of Economic Studies, $42,125-31$.

LELAND, H. (1972), "Theory of the Firm Facing Uncertain Demand," American Economic Review, 62, 278-291.

MATHEWS, S. and MIRMAN, L.J. (1981), "Equilibrium Limit Pricing: The Effects of Private Information and Stochastic Demand" (Discussion Paper 494, Centre for Mathematical Studies in Economics and Management Science, Northwestern University). 
MILGROM, P. and ROBERTS, J. (1982), "Limit Pricing and Entry Under Incomplete Information: An Equilibrium Analysis," Econometrica, 50, 443-460.

OSBORNE, D.K. (197.3), "On the Rationality of Limit Pricing," Journal of Industrial Economics, 22, 71-80.

ROTHȘCHILD, M. and STIGLITZ, J. [1970], "Increasing Risk: I. A Definition:, Journal of Economic Theory, 225-243.

SALOP, S. (1979), "Strategic Entry Deterrence," American Economic Review, 69, 335-338.

SANDMO, A. (1971), "The Competitive Firm Under Price Uncertainty," American Economic Review, 61, 65-73.

SCHELLING, T.C. (1960), The Strategy of Conflict, Cambridge: Harvard University Press.

SPENCE, A.M. (1977), "Entry, Investment and Oligopolistic Pricing," Bell Journal of Economics, 8, 534-544.

(1983), "Contestable Markets and the Theory of Industry Structure: A Review Article", Journal of Economic Literature, 21, 981-990.

SPULBER, D.F. (1981), "Capacity, Output, and Sequential Entry," American Economic Review, 71, 503-515. 